\title{
PLEOMORPHIC LIPOSARCOMA OF PECTORALIS MAJOR MUSCLE IN ELDERLY MAN- CASE REPORT \& REVIEW OF LITERATURE.
}

M. Madan ${ }^{1}$, K. Nischal ${ }^{2}$, Sharan Basavaraj. C. J3.

HOW TO CITE THIS ARTICLE:

M. Madan, K. Nischal, Sharan Basavaraj. C. J. "Pleomorphic liposarcoma of pectoralis major muscle in elderly man- case report \& review of literature". Journal of Evolution of Medical and Dental Sciences 2013; Vol2, Issue 27, July 8; Page: 4922-4927.

ABSTRACT: Primary liposarcoma of the pectoralis major muscle is extremely rare. We report a case of liposarcoma of the pectoralis major muscle which was treated with surgical excision and post operative radiotherapy. Careful followup is mandatory for detecting recurrences.

KEY WORDS: pleomorphic, liposarcoma, pectoralis major.

INTRODUCTION: Liposarcomas are the main group of soft tissue malignant tumours arising from the adipose tissue. They often present as relatively slow growing asymptomatic masses generally located in the thigh gluteal region, retroperitoneum, leg and shoulder area. Pleomorphic variety is the rarest form of liposarcomas and pectoral muscle localization of the tumour is extremely rare [1].

CASE REPORT: We report a 65 year old man admitted with right sided breast mass progressively expanding for six months. Physical examination revealed a soft, non-tender, well shaped, round and mobile mass with a diameter of about $30 \mathrm{~cm}$ in right chest wall. (FIGURE 1)

A contrast enhanced tomography scan (No:24@30805 dated 01/07/10) showed large subcutaneous tumour $(30 * 20 * 10 \mathrm{~cm})$ of the right pectoralis major muscle with no calcification, no necrosis. (FIGURE 2).

On 02-07-2010 under general anaesthesia in a supine position, an oblique elliptical $10 \mathrm{~cm}$ incision over the mass was taken. (FIGURE 3A AND 3B).

The fibres of pectoralis major muscle separated gently and a lobulated yellowish mass was seen. (FIGURE 4A AND 4B)

It was well capsulated A complete resection of the lesion with mastectomy and pectoralis major muscle resection done. Macroscopically clear margins was achieved (FIGURE 5A AND 5B).

On pathological examination, (HPR NO: B-1592-10 dated 09-07-10) the cells were pleomorphic showing vacuolated cytoplasm with lipoblasts. The tumour cells are seen infiltrating the muscle tissue. The microscopic investigation revealed clear margins free of the tumour. Immunohistochemistry revealed a strong positive staining for the S100 antibody and negative for desmin. The final histopathological diagnosis was pleomorphic liposarcoma with myxoid change. (FIGURE 6).

Radiotherapy was planned in the post operative period with a total dose 50 Gy in 25 fractions. The patient is disease free till date.

DISCUSSION: Liposarcoma is a malignant tumor which accounts for $1 \%$ of all human malignancies and approximately $20 \%$ of all mesenchymal malignancies. Intramuscular lesions of the pectoral major muscle mass are extremely rare [2]. 


\section{CASE REPORT}

CT and magnetic resonance imaging (MRI) play an important role in the preoperative evaluation and differentiating [3] diagnosis.

There are five morphologic subtypes of liposarcoma: well differentiated, myxoid, round cell, dedifferentiated, and pleomorphic. Pleomorphic type is the least common form[4] Histological type is the major factor influencing the survival rate. Lower extremity tumors have better prognosis and retroperitoneal ones are worse.

Liposarcoma is primarily surgical disease. The principle of surgery is to remove the tumor entirely and prevent recurrence. Local recurrence largely depends on margin status at time of surgery. Surgery with wide or radical margins is the preferred treatment option with 1-10\% recurrence rates. In this case, there was no invasion into adjacent tissues and chest wall.

According to limited data and case en bloc, tumor and pectoral muscle or chest wall resection with reconstructions in case of invasion may be best surgical procedure. In addition, as Mankin et al. [5] suggested radiotherapy is often helpful in decreasing the local recurrence and metastasis postoperatively

CONCLUSION: In conclusion, pleomorphic liposarcomas are rare neoplasms and to our knowledge, this is the first reported case of pleomorphic liposarcoma of pectoral major muscle. Complete surgical resection and adjuvant radiotherapy appear to prolong survival and improve quality of life in these patients with careful follow-up. The gender, small mass of the breast and huge mass of tumor, and appropriate radiological investigation destine us to proper diagnosis but physicians must be careful in patients with small, smooth, elastic masses which can be misdiagnosis in both physical and radiological examinations.

\section{REFERENCES:}

1. Dei Tos AP (2000) Liposarcoma: new entities and evolving concepts. Ann Diag Path 4:252-66

2. Pant R, Poh AC, Hwang SG (2005). An unusual case of an intramuscular lipoma of the pectoralis major muscle simulating a malignant breast mass. Ann Acad Med Singapore 34:275-6

3. Kransdorf MJ, Bancroft LW, Peterson JJ, Murphey MD, Foster WC, Temple HT(2002) Imaging of fatty tumors: Distinction of lipoma and well-differentiated liposarcoma. Radiology 224:99104

4. Hornick JL, Bosenberg MW, Mentzel T, McMenamin ME, Oliveira AM, Fletcher CD(2004) Pleomorphic liposarcoma: clinicopathologic analysis of 57 cases. Am J Surg Pathol 28:125767

5. Mankin HJ, Hornicek FJ (2005) Diagnosis, classification, and management of soft tissue sarcomas. Cancer Control 12:5-21. 


\section{CASE REPORT}

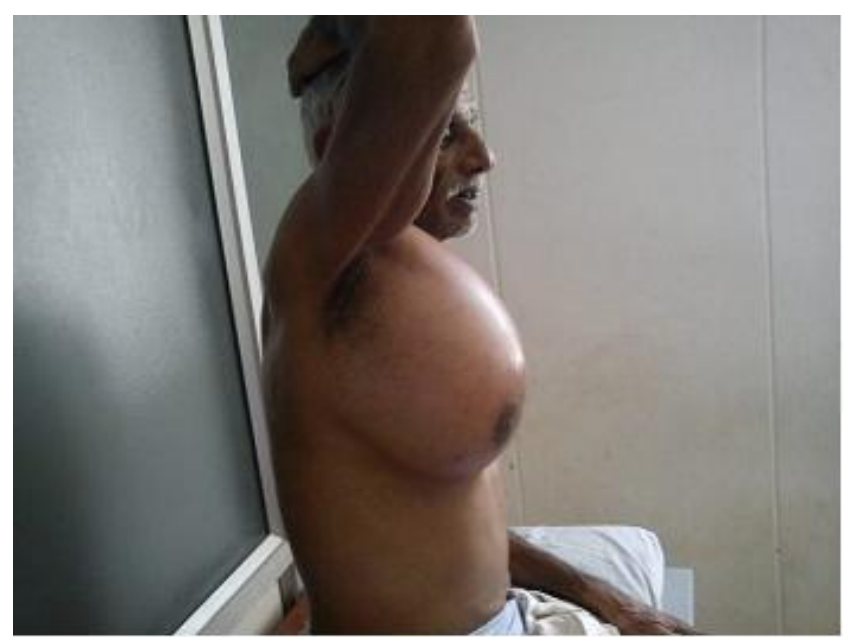

FIGURE 1A: INSPECTION

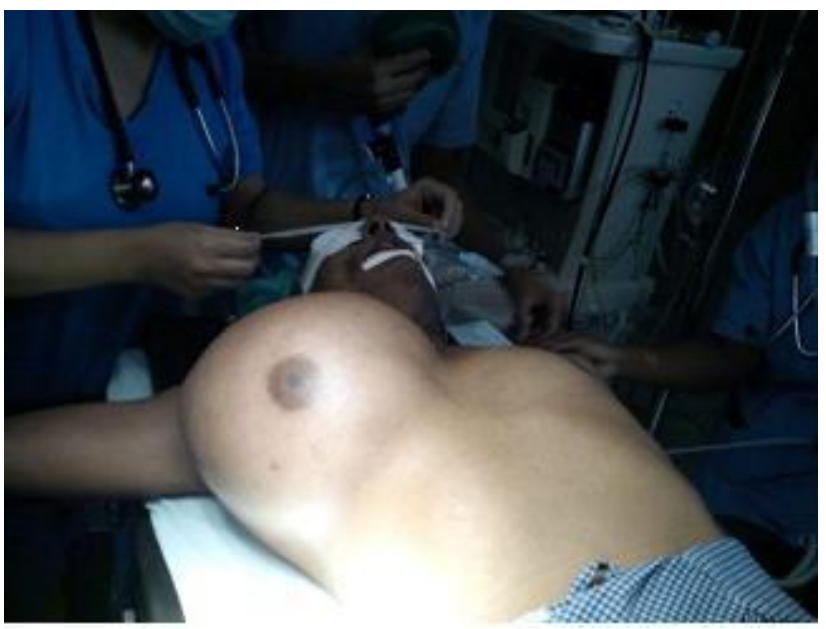

FIGURE 1B: ON TABLE

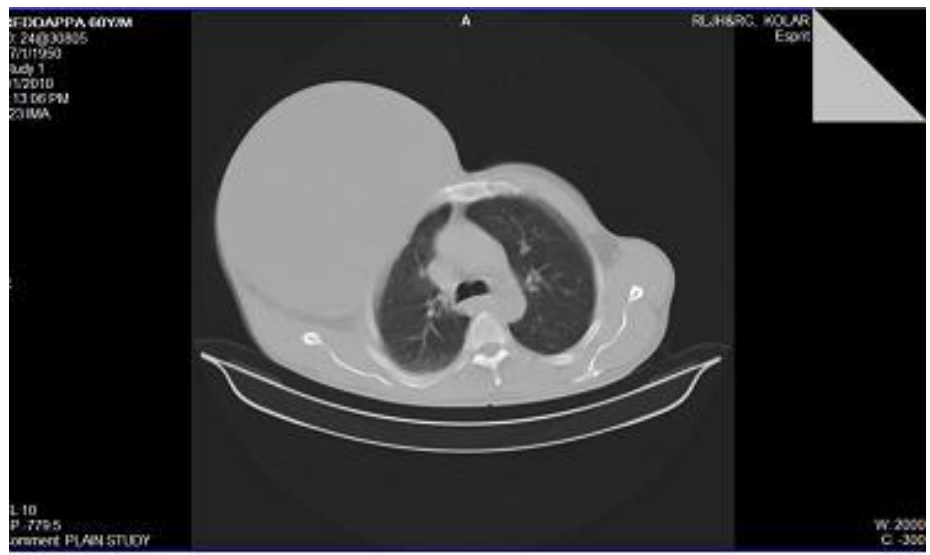

FIGURE 2A: Loss of fat planes and muscle planes 


\section{CASE REPORT}

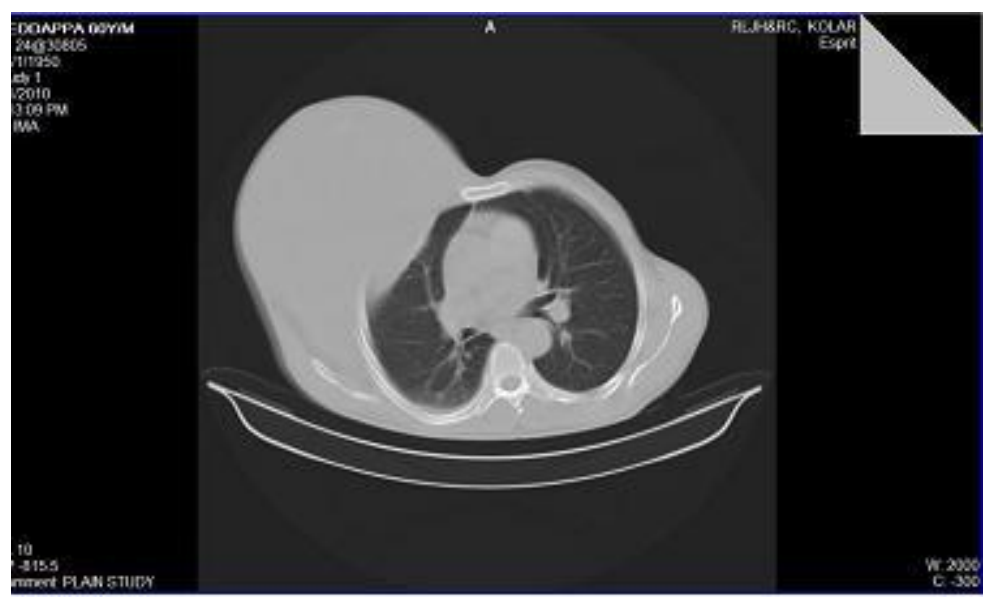

FIGURE 2B: Showing bony erosion of 6 th and 7 th rib with multiple fractures.

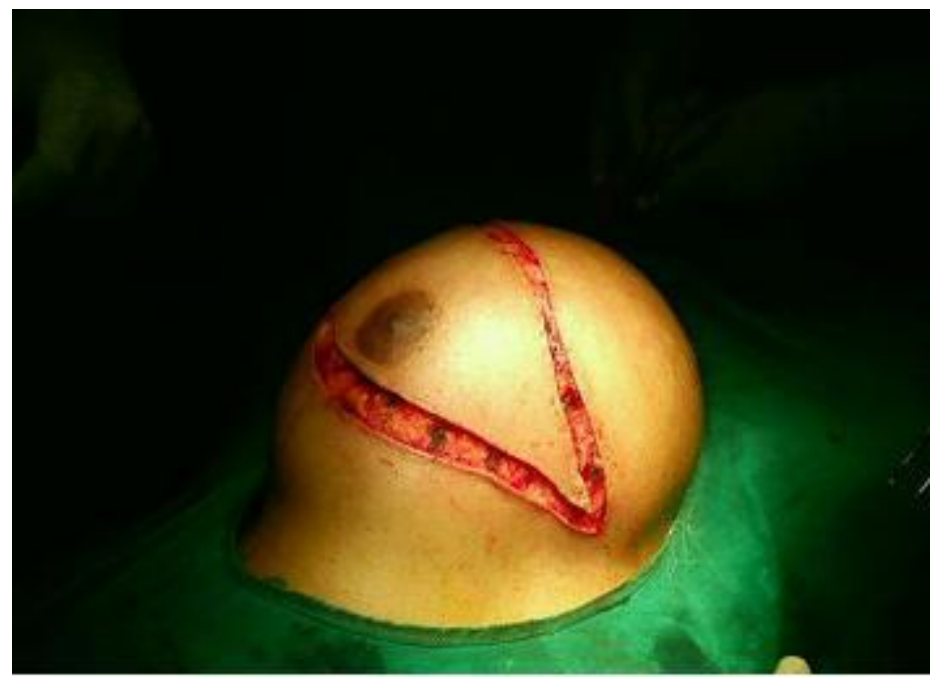

FIGURE 3A: INCISION

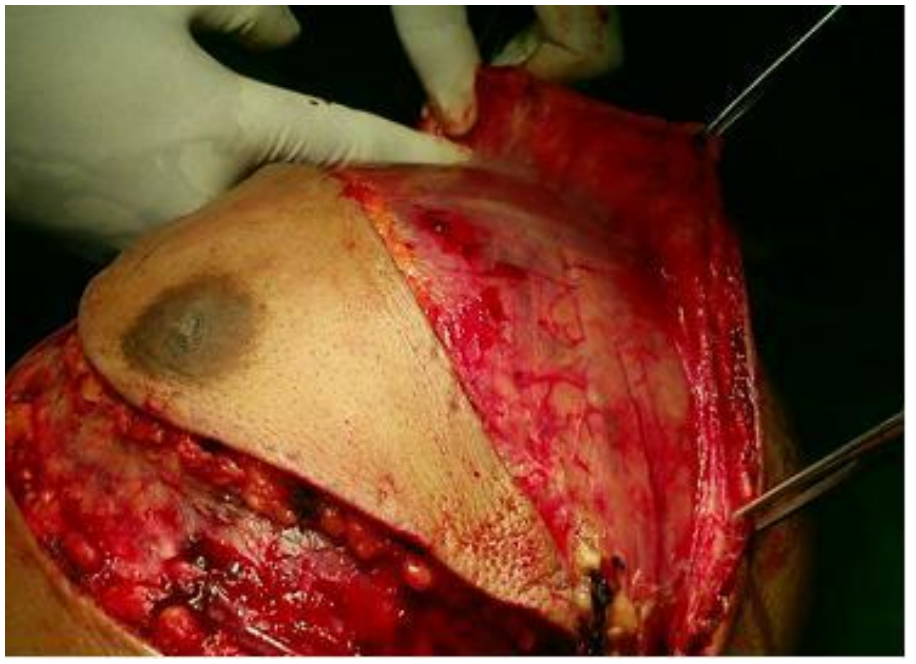

FIGURE 3B: REFLECTING FLAPS 


\section{CASE REPORT}

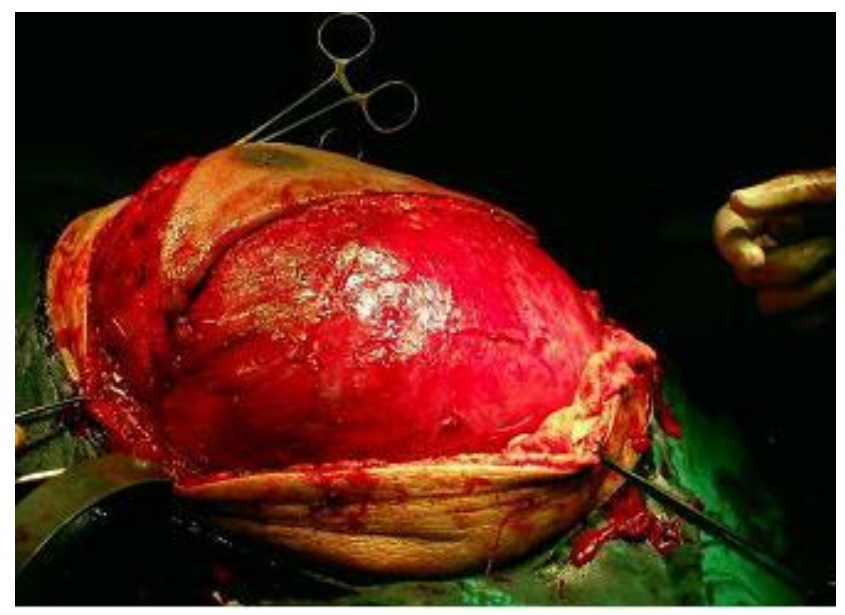

FIGURE 4A: REFLECTED PECTORALIS MAJOR MUSCLE

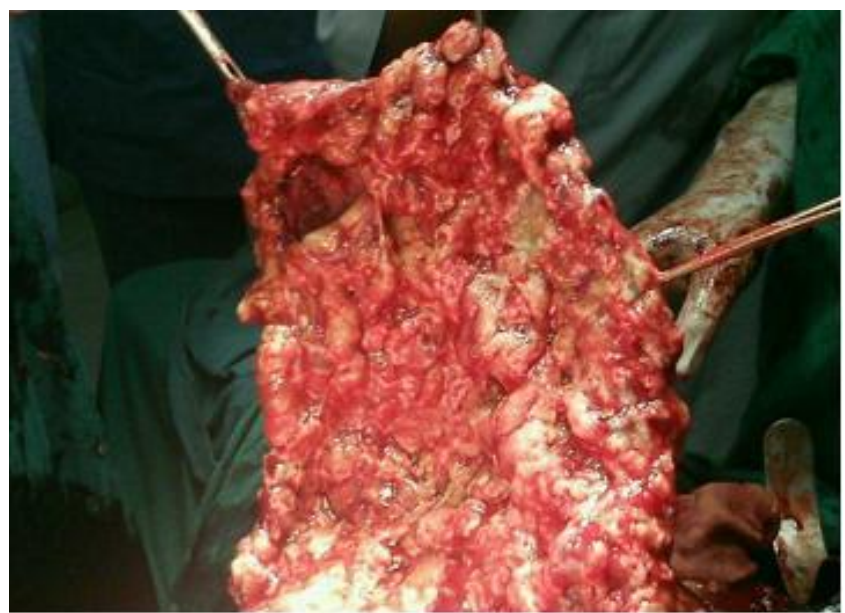

FIGURE 4B: VISION INSIDE THE CAPSULE.

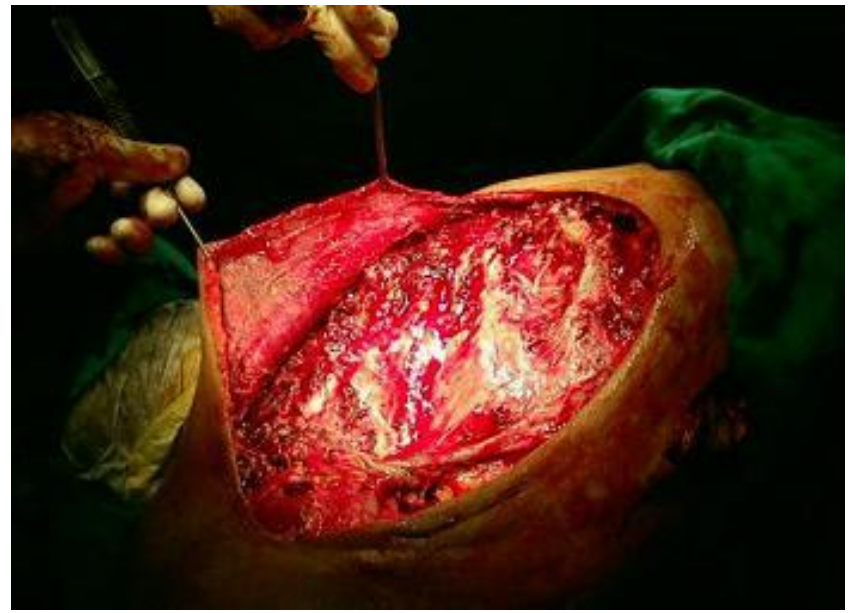

FIGURE 5A: CHEST WALL AFTER COMPLETE RESECTION 


\section{CASE REPORT}

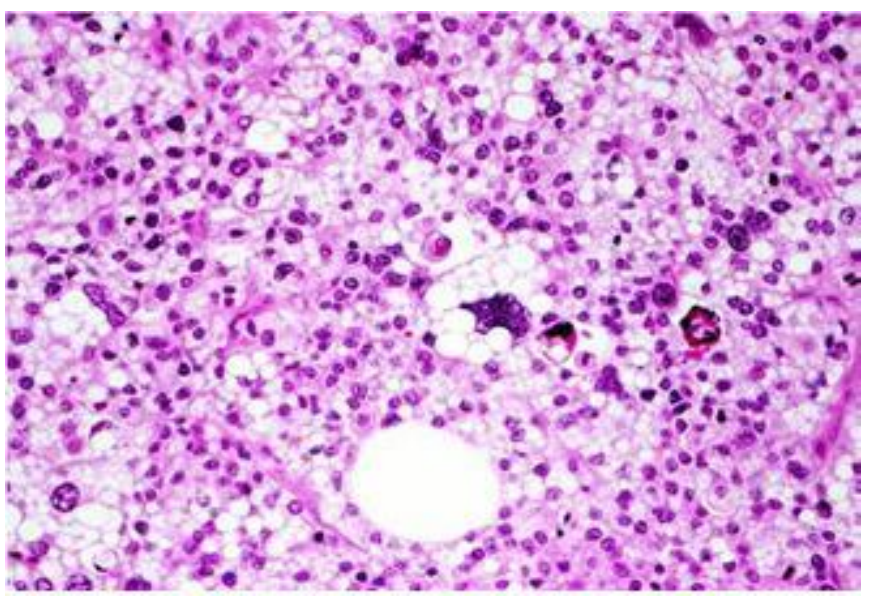

FIGURE 6: PLEOMORPHIC LIPOSARCOMA WITH MYXOID CHANGE.

\section{AUTHORS:}

1. M. Madan

2. K. Nischal

3. Sharan Basavaraj. C. J.

\section{PARTICULARS OF CONTRIBUTORS:}

1. Professor \& HOD, Department of General Surgery, Sri Devaraj Urs Medical College.

2. Associate Professor, Department of General Surgery, Sri Devaraj Urs Medical College.

3. Post- Graduate, Department of General Surgery, Sri Devaraj Urs Medical College.

\section{NAME ADRRESS EMAIL ID OF THE} CORRESPONDING AUTHOR:

Dr. K. Nischal,

Associate Professor, Department of Surgery, Sri Devaraj Urs Medical College, Tamaka, Kolar-563101.

Email: knischal697@gmail.com

Date of Submission: 28/06/2013.

Date of Peer Review: 28/06/2013.

Date of Acceptance: 02/07/2013.

Date of Publishing: 05/07/2013 